\title{
Electrophysiological evaluation in normal-tension glaucoma suspects: a pilot study
}

Dario Messenio¹, Giuseppe Marano², Elia Biganzoli²,3

${ }^{1}$ Eye Clinic, Department of Clinical Science, Luigi Sacco Hospital, University of Milan, Milan, Italy; '2Unit of Medical Statistics and Biometry, Fondazione IRCCS Istituto Nazionale dei Tumori, Milan, Italy; ${ }^{3}$ Department of Clinical Sciences and Community Health, University of Milan, Italy

\section{Abstract}

Purpose: To evaluate the variations of intraocular pressure (IOP), morphometric papillary characteristics, perimetric indices, and electrophysiological parameters, i.e., pattern electroretinogram (PERG) and visual evoked potentials (VEPs), before and after topic hypotonization therapy in normal-tension glaucoma (NTG) suspects. Methods: We evaluated 38 eyes of 20 patients with intraocular pressure of $<21$ $\mathrm{mmHg}$ (measured with Goldmann applanation tonometry), initial glaucomatous optic neuropathy (assessed with Heidelberg Retina Tomograph (HRT): retinal fiber layer (RNFL) and/or linear cup/disk (linear C/D), minimal visual defects (Octopus 101: G2 program), visual acuity of more than $15 / 20$ with best correction, and pathological electrophysiological parameters (valued with pattern electroretinogram and visual evoked potentials), free of systemic or other ocular diseases. All parameters were evaluated at the beginning of the study $\left(\mathrm{T}_{0}\right)$ and after 12 months from the start of the therapy $\left(T_{12}\right)$. A randomized normal control group (27 eyes of 14 subjects) with apparent larger disc cupping underwent all exams at the start of the study and after 12 months.

Results: Among electrophysiological parameters, at the beginning of the study P100 VEPs latency was slightly increased and P100 amplitude was reduced in NTG compared to normal subjects, with no significant variation after 12 months. P50 PERG latency was quite similar between the NTG and normal groups, and showed no modification after therapy. Compared to normal subjects, P50N95 complex

Correspondence: Dario Messenio, via Domenichino 49, Milano 20149, Italy.

E-mail:dmessenio@virgilio.it 
PERG amplitude in NTG was reduced and showed a slight increase after 12 months (1.8 vs 1.5; 2.4 vs 1.9 micronvolts, with different checkerboard spatial frequency). Cortical-retinal time (CRT) was slightly delayed in NTG and showed no modification after therapy. Among visual field indices, mean defect (MD) and corrected loss variance (CLV) were slightly higher in NTG, and showed no significant modification after therapy. Among morphometric optic nerve head characteristics, linear C/D and RNFL thickness were quite similar between the NTG and normal groups, and showed no modification after therapy. IOP was also similar between NTG and normal subjects, and decreased after therapy in the NTG group.

Conclusion: From the perspective of an integrated diagnostic, electrophysiological tests (VEPs and PERG) may provide a more sensitive measure of retinal ganglion cell (RGC) integrity and help to distinguish between normal-tension glaucoma suspects before perimetric alterations are evident, and normal subjects with apparent larger disc cupping.

Keywords: pattern electroretinogram (PERG), visual evoked potentials (VEPs), normal-tension glaucoma (NTG) suspects, minimal visual defects, initial glaucomatous optic neuropathy

\section{A short guide to read electrophysiological parameters}

\section{Pattern electroretinogram (PERG)}

The pattern electroretinogram (PERG) represents an objective and direct measure of retinal ganglion cell (RGC) function. It is a retinal biopotential evoked by a temporally modulated patterned stimulus (checkerboard or grating) of constant mean luminance. The PERG waveform depends on the temporal frequency of the stimulus. At low temporal frequencies $(<6$ reversals per second (rps), equivalent to $3 \mathrm{~Hz}$ ), transient PERGs are obtained: the PERG waveform in normal subjects usually consists of a small initial negative component with a peak time (i.e., latency) of $35 \mathrm{msec}$ (N35), followed at $45-60 \mathrm{msec}$ by a much larger positive component (P50), and a large negative component at about 95 msec (N95). In glaucoma analysis, P50N95 complex amplitude (in micronvolt) - calculated from P50 peak to N95 peak - and P50 implicit time (or latency) (in $\mathrm{msec}$ ) are measured with different spatial frequencies: either with checkerboard subtending 30' of arc of visual angle or 15' (smaller).

\section{Visual evoked potentials (VEPs)}

Visual evoked potentials (VEPS) characterize the state of the whole visual pathway. The waveform of the VEPs evoked by contrast reversal of pattern stimuli depends on the temporal frequency of the stimulus. Considerations 
are the same as those for PERG. At low temporal frequencies ( $<6$ reversals per second (rps), equivalent to $3 \mathrm{~Hz}$ ), transient VEPs are obtained: VEPs waveforms consist of an initial negative component with a peak time of approximately 75 msec (N75), followed by a larger positive component (P100) at 100-110 msec, and by a large negative component at 120-140 msec (N135). P100 latency (in $\mathrm{msec}$ ) and amplitude (in micronvolt) are measured with different spatial frequencies: either with checkerboard subtending 30' of arc of visual angle or 15' (smaller).

Cortical-retinal time (CRT) is an electrophysiological index that analyzes neural conduction in post-retinal visual pathways; it is derived from simultaneous recordings of VEPs and PERGs and represents the latency difference between P50 PERG and P100 VEPs.

\section{Introduction}

Glaucoma is a multifactorial optic neuropathy characterized by progressive loss of retinal ganglion cells (RGC), changes in optic disk morphology, and visual field defects. Intraocular pressure (IOP) is a recognized risk factor for the development and progression of glaucomatous damage: multicenter studies have found that a $1 \mathrm{mmHg}$ reduction decreased the risk of damage progression by $10 \%$, and that conversion from ocular hypertension to manifest glaucoma is decreased by reducing IOP. ${ }^{1,2}$ A particular type of open-angle glaucoma, normal-tension glaucoma (NTG), has a typical glaucomatous optic neuropathy evolution with untreated IOP below 21 $\mathrm{mmHg} .{ }^{3-5}$ Several population studies have suggested an incidence of NTG between $20 \%$ and $40 \%$ for all open-angle glaucomas. ${ }^{6,7}$ IOP is recognized as the most important risk factor for the development or progression of glaucomatous damage, even if pressure reduction does not necessarily slow or halt disease progression. ${ }^{8,9}$ In fact, in NTG other IOP-independent factors concur to the progression of the disease, including migraine, disk haemorrhage, occlusive vascular diseases, abnormal ocular blood flow, systemic hypotension, and sleep apnoea, ${ }^{10-12}$ even if there still are individual responses between diagnostic exams. Specifically, patients with NTG show a greater reduction in nocturnal blood pressure compared to healthy subjects, which is correlated to a more rapid progression of glaucoma. ${ }^{13-15}$

In addition to damaging RGC, glaucoma can also damage the post-retinal mechanism at the level of the lateral geniculate nucleus (LGN) of the thalamus and the primary visual cortex (V1). ${ }^{16}$ Hence, glaucoma can be associated with profound degenerative effects in the visual brain. Studies on experimental glaucoma in primates show neural degeneration of the $\mathrm{LGN}^{17-20}$ and activity changes in the visual cortex..$^{19}$ Degeneration of the LGN and visual cortex has also been demonstrated in human glaucoma. ${ }^{16}$ 
Among diagnostic exams for glaucoma, the pattern electroretinogram (PERG) stands as a direct indicator of RGC function. ${ }^{21,22}$ PERG amplitude decreases with increasing age in normal subjects, which may be due to neural loss as well as to reduced retinal illuminance resulting from retinal miosis and reduced image contrast due to cataract or other opacities of optical media; therefore, response must be normalized for age. ${ }^{23,24}$

PERG reflects ganglion-diffuse rather than focal damage, ${ }^{25,26}$ so correlations between altered PERGs and visual fields are not necessarily found. ${ }^{27,28} \mathrm{RGC}$ loss above $30 \%$ is associated with statistically significant changes in visual field sensitivity ${ }^{29}$, so the visual field is not impaired in ocular hypertension or early manifest glaucoma. ${ }^{30}$ Caprioli identified two distinct types of glaucoma field defects: a more diffuse loss of visual field sensitivity, correlated to IOP, and a less pressure-dependent, localized type. The first type may be due to diffuse dysfunction leading to progressive concentric enlargement of the optic nerve cup; as it is a mass response reflecting diffuse RGC dysfunction, PERG is often impaired in this type of glaucoma. ${ }^{31}$ Caprioli believes that the second type, i.e., glaucoma with focal visual field defects, is more correlated with vascular factors. In this type of glaucoma, PERG may still be normal until the majority of RGC are affected. ${ }^{32}$

PERG is altered in glaucoma as well as in many cases of ocular hypertension $(\mathrm{OHT}){ }^{33-36}$ Several authors who have performed human studies find PERG to be a predictive value to identify those patients with elevated IOP who develop glaucoma before visual field changes occur; ${ }^{37-40}$ given that none of the eyes with initially normal PERG develop glaucomatous field defects ${ }^{41}$ moreover Philippin, in a ten-year longitudinal study, found that $8 \%$ of eyes develop manifest glaucoma (defined by visual field defect) with high sensitivity and specificity. ${ }^{40,42}$ In experimental glaucoma studies in monkeys, Marx found a reduction of PERG amplitude without evidence of cupping, ${ }^{43}$ in mice, Saleh and Porciatti show a progressive reduction of inner retina function with retinal fiber layer (RNFL) relatively spared: PERG amplitude reaches the noise level in many eyes when RNFL thickness decreases by $50 \% .44,45$

Some authors have emphasized the correlation between PERG and progress of vertical cup-to-disc ratio, ${ }^{46}$ optic disk RNFL thickness loss measured by optical coherence tomography (OCT), ${ }^{47,48}$ and cup shape measure of the Heidelberg Retina Tomograph (HRT). ${ }^{49,50}$

PERG has a higher sensibility to detect glaucomatous defects $\mathrm{s}^{39,51,40}$ and is abnormal in most patients with manifest disease. ${ }^{49,52,47,51}$ PERG impairment always precedes visual field defects. ${ }^{53}$ As it reflects diffuse ganglion damage, there is a strong correlation between PERG and mean defect (MD) visual field index and a weak correlation with correct pattern standard deviation (CPSD) or corrected loss variance (CLV), both of which analyze local defects. ${ }^{48,53}$ There is no linear relationship between P50N95 amplitude and visual field loss and, in some cases, PERG changes can precede detectable field loss because PERG is particularly sensitive to early damage. ${ }^{54}$ 
As referred above, PERG reflects the total amount of electrophysiological activity of RGC, i.e., represents an objective and direct measure of RGC function. Analysing the structure-function relationship in experimental and human studies, Marx ${ }^{46}$ Ventura, ${ }^{55}$ and North $^{56}$ suggested the hypothesis that there may be a stage of reversible dysfunction prior to RGC death. This period of dysfunction may happen long before ganglion cell loss. In glaucoma suspects or in early glaucoma, a reduction in PERG amplitude may be due to early RGC dysfunction. This dysfunction is potentially reversible and may be restored after IOP reduction. ${ }^{55}$ This improvement occurred not only in ocular hypertension (OHT) or hypertensive glaucoma (primary open-angle glaucoma, POAG), ${ }^{46}$ but also in NTG. ${ }^{56}$ Particularly in early glaucoma, after lowering IOP Ventura found a positive change in slope steepness that may indicate that the progressive degradation of RGC function has slowed down. ${ }^{57}$ Compared to POAG, PERG improvements in NTG were associated with smaller reductions of IOP; ${ }^{55}$ perhaps RGC dysfunction in NTG occurs at a lower IOP and, in turn, PERG improvements occur after smaller IOP reductions. However, small improvements in eyes with advanced visual field defects may be explained by fewer quantities of surviving RGC in the advanced stages of NTG.

Visual evoked potentials (VEPS) characterize the state of the whole visual pathway. In glaucomatous patients, there is a delay of P100 latency and/or P100 amplitude reduction. ${ }^{58,59,51}$ Parisi found a high specificity of VEPs in identifying normal subjects. ${ }^{51}$ VEPs show reduced amplitude in OHT and manifest glaucoma. ${ }^{60}$ Cortical-retinal time (CRT) is an electrophysiological index that analyzes neural conduction in post-retinal visual pathways; it is derived from simultaneous recordings of VEPs and PERGs ${ }^{61}$ and represents the latency difference between P50 PERG and P100 VEPs. Cortical-retinal time is unchanged in OHT, but increases as the disease progresses ${ }^{47}$ and is correlated with a reduction in PERG amplitude so that signal transmission is progressively slower (revealed by a greater increase of P100 latency). Moreover, there is a correlation with optic nerve fiber thinning, measured by $O C T .{ }^{47}$ VEPs reflect the activity of the later stages in the visual processing chain, and are less affected by glaucoma than PERG.

In this study, we tested the hypothesis that electrophysiological dysfunctions are present in NTG suspects with early structural damage and no perimetric defect. Additionally, any structural or functional variations were assessed twelve months after starting therapy.

\section{Methods}

The study was approved by the Hospital Medical Ethics Committee, and informed consent was obtained from the subjects following an explanation of the nature and possible consequences of the study. Healthy control subjects and early-stage glaucoma patients were recruited at the Sacco Hospital eye clinic in Milan, Italy. 


\subsection{Patients with suspected NTG}

Twenty subjects (38 eyes) with suspected normal-tension glaucoma were recruited. All patients underwent a complete clinical examination including best-corrected visual acuity, Goldmann applanation tonometry, optic nerve head assessment by slit lamp binocular indirect ophthalmoscopy, scanning laser tomography (Heidelberg Retina Tomograph (HRT), Germany), perimetry (Octopus 101: G2 program for glaucoma; Interzeag, Schlieren, Switzerland), VEPs and PERG recording (Biomedica Mangoni, Pisa, Italy).

Inclusion criteria were:

1. visual acuity of more than $15 / 20$ with best correction;

2. untreated IOP (measured with Goldmann applanation tonometry) on a diurnal pressure curve inferior to $21 \mathrm{mmHg}$;

3. initial glaucomatous optic neuropathy evaluated with HRT in conjunction with the following inclusion criteria: 1) one sector measurement labelled "borderline" or "outside of normal" at Moorfield Regression Analysis; 2) retinal nerve fibre layer (RNFL) less than 200; 3) linear cup-disk (linear C/D) more than 600;

4. alteration of electrophysiological parameters, namely, decreased P50N95 PERG complex amplitude or/and decreased VEPs P100 wave amplitude. Values differing by less than two standard deviations from the correct normative value for age were considered non-pathological;

5. visual field indices: mean defect (MD) and correct loss variance (CLV), considering values "borderline" or "1st Stage" according to Glaucoma Staging System 2 perimetric stadiation. ${ }^{62,63}$

Exclusion criteria were:

1. history of refractive surgery;

2. high myopia;

3. other ocular or systemic diseases;

4. patients already in therapy or with other ocular or systemic diseases.

\subsection{Healthy subjects}

An age-matched control group of 14 healthy subjects (27 eyes) with the same morphological alterations (RNFL less than 200 and linear cup-disk (linear C/D) more than 600) but normal PERG, VEPs, and visual field indices; no ophthalmic diseases and no family history of glaucoma.

We analyzed these two groups at the start of the study $\left(T_{0}\right)$ and after 12 months $\left(T_{12}\right)$. Glaucomatous patients underwent hypotonizing therapy with prostaglandin eye drops, one drop a day; the controls did not undergo therapy.

\subsection{Electroretinography}

Electrophysiological tests (VEPs and PERG) were recorded monocularly and simultaneously. 


\subsection{PERG technique}

A small silver chloride skin (active and reference) electrode was positioned on the lower eyelids. A skin electrode at the midfrontal position (in Fpz scalp) served as ground. PERG were recorded simultaneously with VEPs, with 30-minute and 15-minute black-and-white checkerboard pattern stimulus, $45 \mathrm{~cd} / \mathrm{m}^{2}$ mean luminance, reversing two times per second (square wave reversal) or counter phased at $1 \mathrm{~Hz}$ (thus evoking transient responses) at 98\% contrast between blackand-white squares. Signals were amplified (50000 times) and filtered (pass band 1-100 Hz). The stimuli were generated on a cathode-ray tube monitor subtending $24^{\circ}$ at a viewing distance of $114 \mathrm{~cm}$.

At low temporal frequencies ( $<6$ rps), transient PERGs were obtained. The PERG waveform consists of a small initial negative component with a peak time of approximately $35 \mathrm{~ms}$ (N35), followed at $45-60 \mathrm{~ms}$ by a larger positive component (P50). The following wave is a large negative component at $90-100 \mathrm{~ms}$ (N95). P50 peak time (or latency) and P50N95 complex amplitude (i.e., from the peak of P50 to the peak of N95) were measured.

\subsection{Visual evoked potentials (VEPs) technique}

The scalp electrodes were placed according to the International 10/20 System. The active electrode was placed on the scalp over the visual cortex at $\mathrm{Oz}$ with the reference electrode at Fz. A skin electrode at the midfrontal position (in Fpz scalp) served as ground electrode.

VEPs were recorded simultaneously with PERG, with 30-minute and 15-minute black-and-white checkerboard pattern stimulus with $45 \mathrm{~cd} / \mathrm{m}^{2}$ mean luminance, reversing two times per second (square wave reversal) or counter phased at 1 $\mathrm{Hz}$ (thus evoking transient responses) at $98 \%$ contrast between black and white squares. Signals were amplified ( 50000 times) and filtered (pass band $1-100 \mathrm{~Hz}$ ). The stimuli were generated on a cathode-ray tube monitor subtending $24^{\circ}$ at a viewing distance of $114 \mathrm{~cm}$.

At low temporal frequencies ( $<6 \mathrm{rps}$ ), the pattern-reversal VEP waveform consists of N75, P100, and N135 peaks. P100 peak time (or latency) and P100 amplitude were measured.

\subsection{Perimetry and visual field criteria}

Octopus 101: G2 program for glaucoma; Interzeag, Schlieren, Switzerland Glaucoma Staging System 2 (GSS2) perimetric stadiation was used, which considers visual field defects by analyzing perimetric indices: MD and CLV. ${ }^{62,63}$ We included in this study no defect or initial defects: "borderline" (MD between 2,5 and 3; CLV between 3 and 4) or "1st stage" (MD between 3 and 6; CLV between 4 and 6) in two consecutive visual fields..$^{62,63}$ 


\subsection{HRT technique}

The HRT is a confocal scanning laser imaging device for the analysis of glaucomatous optic disk topography. ${ }^{64,65}$ With Moorfield Regression Analysis (MRA) for each sector of the optic nerve head $(\mathrm{ONH})$, patients were included with at least a "borderline" global rim area, i.e., at least one measure outside the norm between $95 \%$ and $99 \%$ confidence interval ( $\mathrm{Cl}$ ), linear cup disc (linear C/D) more than 0.55 , and mean retinal nerve fiber layer thickness (RNFL thickness) less than $200 .{ }^{66}$

\subsection{Statistics}

The main aim of the statistical analysis was to describe and quantify the diagnostic parameters for two groups, NTG suspects and healthy subjects, respectively. The analysis was performed on a sample of 38 eyes of patients $(n=20)$ with suspected NTG, and 27 eyes of healthy subjects $(n=14)$. For each eye, the following variables were available, both at $\mathrm{T}_{0}$ (start of the study) and $\mathrm{T}_{12}$ (twelve months later), except for pachimetry, which was recorded only at $\mathrm{T}_{0}$ :

1. electrophysiological measurements: latency and amplitude of the P50 PERG wave and P100 VEP wave, with 30-minutes and 15-minutes checkerboard pattern stimulus;

2. visual field indices: mean defect (MD), correct loss variance (CLV);

3. morphometric parameters: RNFL thickness, linear C/D;

4. intraocular pressure (IOP);

5. pachymetry.

Furthermore, CRT was defined as the difference between P100 VEPs wave latency and P50 PERG wave latency.

The variables above were summarized using means and standard deviations. A multivariate descriptive analysis was performed, using principal component analysis (PCA) methods, ${ }^{67}$ in order to identify possible patterns of electrophysiological measurements and other parameters in the two groups (NTG and healthy subjects), and to evaluate the correlation among such features. A brief sketch of such methods is reported in the following box.

The strategy of analysis was the following one:

1. In a preliminary step, the assumption of linear correlation among the variables under examination was checked by examining correlation coefficients (Pearson's $r$ and Spearman's rho) and scatterplots for each couple of variables.

2. Two separate PCAs were performed, for electrophysiological measurements and the remaining variables, respectively. In each one, measurements at $T_{0}$ of each variable were used as active variables. This allowed to focus attention on the relationships among the elements that could be potentially used for an early diagnosis. The association among measurements at $\mathrm{T}_{0}$ and $\mathrm{T}_{12}$ was evaluated by including the latter ones in the PCA as supplementary variables. The number of relevant principal components was determined 
by examining the scree-plot. Both variables and individuals (i.e., eyes) were represented through principal component biplots. ${ }^{68}$

A further aim was to estimate the average values of the measurements of all the variables and respective differences:

1. between eyes of NTG patients and healthy subjects, at $T_{0}$ and $T_{12}$;

2. between $\mathrm{T}_{12}$ and $\mathrm{T}_{0}$ for each of the two groups.

To such end, the standard statistical methods based on the assumption of independent and identically distributed (i.i.d.) observations were not adequate. In fact, the i.i.d. assumption was violated by the presence of both repeated measurements for each eye and the correlation between measurements of fellow eyes. Therefore, the estimates were obtained by mixed effects ANOVA methods. ${ }^{69}$ In each ANOVA model:

1. each variable was included as a response variable;

2. the time of measurement (start of study; 12 months later) and group (NTG; healthy) were included as categorical predictors, with both simple effects and interaction effect;

3. to account for the above-mentioned sources of correlation, two random effects, corresponding to subjects and eyes, respectively, were also included. The results were reported in terms of estimated averages with respective $95 \% \mathrm{Cl}$. The $\mathrm{Cl}$ for the four differences indicated above were corrected with the Bonferroni rule.

The statistical analysis was performed using the $r$ sofware $^{70}$ with additional nlme ${ }^{71}$ and multcomp ${ }^{72}$ packages.

\section{Principal component analysis: brief methodological notes}

PCA belongs to a wide class of statistical analyses targeted at describing the main features of the distribution of a large set of inter-related variables by reducing the dimensionality of the data. In PCA, this reduction is achieved by transforming the variables into a new set of variables, called principal components, which are ordered in such a way that the first few - most frequently the first one or two - retain most of the variation present in all the original variables. Thus, the principal components may synthesize the main patterns of correlation among the original variables (as measured by the linear correlation coefficient, Pearson's r) and, according to such patterns, identify groups (clusters) of subjects provided of the homogeneous features of the original variables.

PCA techniques allow to plot all the original variables and/or individuals within a few plots, thus giving a straightforward visual representation of the features under examination. Usually, variables are represented by vectors, and individuals by points. The interpretation of the plots follows conventional rules 
based on the relative positions among such elements:

1. For each couple of variables: if the corresponding vectors point in the same direction (the angle is close to 0 degrees), the variables are positively correlated. If two vectors point in opposite directions (the angle is close to 180 degrees), the variables are negatively correlated. If two vectors are orthogonal (the angle is close to 90 degrees), there is a low correlation between the variables.

2. For each couple of individuals, the distance between the corresponding points indicates their similarity: a short distance indicates individuals with comparable values of the original variables, whereas a long distance indicates 'heterogeneous' individuals.

3. For each point (individual), the patterns of the original variable are derived by projecting the point onto the vectors. Considering each vector as an axis, the distances between the origin and the projections of the points indicate the magnitude of the corresponding variables.

For further details, see the cited monography by Jolliffe. ${ }^{67}$

\section{Results}

Means and standard deviations of the variables of interest are reported in Table 1. In the multivariate analysis, no complex, i.e., non-linear relationship emerged from the examination of correlation coefficients and scatterplots. In the first PCA (electrophysiological characteristics), according to the scree-plot the first principal component provides an adequate synthesis of the variables under examination. The proportion of total variability of data explained by the first principal component is $48.6 \%$. The patterns emerging from the biplot (Fig. 1a) are quite clear:

1. A global positive correlation emerged among measurements of P100 VEP and P50 PERG amplitudes at $T_{0}$ (the vectors corresponding to such variables are overall directed toward the same direction) of moderate or moderate/high amount. In agreement with this, the values of Pearson's index of correlation (Pearson's r) vary from 0.46 to 0.88 .

2. Similarly, a positive correlation emerged among latency measurements at $\mathrm{T}_{0}$, more pronounced between the two measurements of the P100 VEP wave $(r=0.83)$, whereas the correlation of the latency of the P50 PERG wave with 30-minutes checkerboard pattern (P50/30') with the other variables is low ( $r$ ranging from 0.13 to 0.23 ) (the angles between the vector corresponding to P50/30' and the vectors representing the other variables are overall nearly $\left.90^{\circ}\right)$. 
Table 1. Descriptive synthesis of diagnostic parameters

Data were reported as mean and standard deviations. NTG = eyes of patients with suspected normal tension glaucoma; Healthy = eyes of healthy subjects. Electrophysiological parameters: L100 and L50 = latency of P100 VEP and P50 PERG waves, respectively; A100 and A50 = amplitude of P100 VEP and P50N95 complex PERG waves, respectively. Text: /15' and /30' indicate measurements taken with 15-minutes and 30-minutes checkerboard pattern stimulus, respectively. Visual field indices: $M D=$ mean defect; CLV = correct loss variance. Morphometric parameters: RNFL = RNFL thickness; Lin.C/D = linear C/D. IOP = intraocular pressure. $\mathrm{PAC}=$ pachimetry.

\begin{tabular}{|c|c|c|c|c|}
\hline \multirow[b]{2}{*}{$\begin{array}{l}\text { VEP and PERG } \\
\text { measurements }\end{array}$} & \multicolumn{2}{|c|}{ NTG } & \multicolumn{2}{|c|}{ Healthy } \\
\hline & $\begin{array}{c}\text { Left eye } \\
\text { Mean (SD) }\end{array}$ & $\begin{array}{l}\text { Right eye } \\
\text { Mean (SD) }\end{array}$ & $\begin{array}{l}\text { Left eye } \\
\text { Mean (SD) }\end{array}$ & $\begin{array}{l}\text { Right eye } \\
\text { Mean (SD) }\end{array}$ \\
\hline $\begin{aligned} \text { L100/15': } & \text { at } \mathrm{T}_{0} \\
& \text { at } \mathrm{T}_{12}\end{aligned}$ & $\begin{array}{c}124.0(9.1) \\
122.4(10.6) \\
\end{array}$ & $\begin{array}{l}123.9(11.6) \\
122.0(10.4) \\
\end{array}$ & $\begin{array}{l}111.2(6.2) \\
113.3(7.2) \\
\end{array}$ & $\begin{array}{l}111.5(5.0) \\
110.7(4.8) \\
\end{array}$ \\
\hline $\begin{aligned} \text { L100/30': }^{\prime} & \text { at } \mathrm{T}_{0} \\
& \text { at } \mathrm{T}_{12}\end{aligned}$ & $\begin{array}{l}114.9(8.3) \\
115.9(6.8) \\
\end{array}$ & $\begin{array}{l}114.0(8.6) \\
114.0(8.8) \\
\end{array}$ & $\begin{array}{l}105.2(6.0) \\
106.3(8.9) \\
\end{array}$ & $\begin{array}{l}105.6(6.9) \\
105.6(6.1) \\
\end{array}$ \\
\hline $\begin{array}{r}A 100 / 15^{\prime}: \text { at } T_{0} \\
\text { at } T_{12}\end{array}$ & $\begin{array}{l}8.3(3.2) \\
9.2(3.4) \\
\end{array}$ & $\begin{array}{l}8.0(3.8) \\
8.8(3.4) \\
\end{array}$ & $\begin{array}{l}14.5(4.6) \\
13.9(4.6) \\
\end{array}$ & $\begin{array}{l}14.9(5.5) \\
15.3(5.7) \\
\end{array}$ \\
\hline $\begin{array}{r}A 100 / 30 ': \text { at } T_{0} \\
\text { at } T_{12}\end{array}$ & $\begin{array}{l}7.7(3.0) \\
7.7(2.5) \\
\end{array}$ & $\begin{array}{l}8.5(3.3) \\
8.8(3.4) \\
\end{array}$ & $\begin{array}{l}13.1(5.0) \\
13.8(6.4) \\
\end{array}$ & $\begin{array}{l}14.4(4.2) \\
15.3(5.6) \\
\end{array}$ \\
\hline $\begin{array}{ll}\text { L50/15': } & \text { at } \mathrm{T}_{0} \\
& \text { at } \mathrm{T}_{12}\end{array}$ & $\begin{array}{l}63.1(8.1) \\
61.6(7.5)\end{array}$ & $\begin{array}{l}61.0(9.4) \\
59.8(6.6)\end{array}$ & $\begin{array}{l}61.5(6.5) \\
59.0(6.1)\end{array}$ & $\begin{array}{l}58.9(5.8) \\
57.1(4.7) \\
\end{array}$ \\
\hline $\begin{array}{ll}\text { L50/30': } & \text { at } \mathrm{T}_{0} \\
& \text { at } \mathrm{T}_{12}\end{array}$ & $\begin{array}{l}58.9(8.3) \\
58.2(7.2) \\
\end{array}$ & $\begin{array}{l}56.7(7.8) \\
54.7(4.8) \\
\end{array}$ & $\begin{array}{l}57.5(4.0) \\
56.1(5.6) \\
\end{array}$ & $\begin{array}{l}55.7(5.2) \\
55.6(5.3) \\
\end{array}$ \\
\hline $\begin{aligned} \text { A50/15': } & \text { at } T_{0} \\
& \text { at } T_{12}\end{aligned}$ & $\begin{array}{l}1.5(0.6) \\
1.8(0.6) \\
\end{array}$ & $\begin{array}{l}1.5(0.6) \\
1.8(0.8) \\
\end{array}$ & $\begin{array}{l}2.5(0.7) \\
2.6(0.7) \\
\end{array}$ & $\begin{array}{l}2.2(0.4) \\
2.4(0.8) \\
\end{array}$ \\
\hline $\begin{aligned} & \text { A50/30': } \text { at } T_{0} \\
& \text { at } T_{12} \\
&\end{aligned}$ & $\begin{array}{l}1.9(0.6) \\
2.6(0.9) \\
\end{array}$ & $\begin{array}{l}1.9(0.6) \\
2.2(0.7) \\
\end{array}$ & $\begin{array}{l}2.7(0.4) \\
2.9(0.9) \\
\end{array}$ & $\begin{array}{l}2.7(0.4) \\
3.0(0.9)\end{array}$ \\
\hline $\begin{aligned} \text { CRT/15': }^{\prime} & \text { at } T_{0} \\
& \text { at } T_{12}\end{aligned}$ & $\begin{array}{c}60.9(13.7) \\
60.8(9.2) \\
\end{array}$ & $\begin{array}{l}62.9(10.9) \\
62.2(12.6) \\
\end{array}$ & $\begin{array}{l}49.6(5.9) \\
54.3(4.1) \\
\end{array}$ & $\begin{array}{l}52.6(7.0) \\
53.6(5.9) \\
\end{array}$ \\
\hline $\begin{aligned} \text { CRT/30': } & \text { at } T_{0} \\
& \text { at } T_{12}\end{aligned}$ & $\begin{array}{c}56.0(11.8) \\
57.8(9.8)\end{array}$ & $\begin{array}{c}57.2(11.0) \\
59.2(9.6)\end{array}$ & $\begin{array}{l}47.8(6.3) \\
50.2(9.3)\end{array}$ & $\begin{array}{l}49.9(6.0) \\
50.0(7.9)\end{array}$ \\
\hline
\end{tabular}




\begin{tabular}{|ll|c|c|c|c|}
\hline \multirow{2}{*}{} & \multicolumn{2}{|c|}{ NTG } & \multicolumn{2}{c|}{ Healthy } \\
\hline $\begin{array}{l}\text { Other } \\
\text { characteristics }\end{array}$ & $\begin{array}{c}\text { Left eye } \\
\text { Mean (SD) }\end{array}$ & $\begin{array}{c}\text { Right eye } \\
\text { Mean (SD) }\end{array}$ & $\begin{array}{c}\text { Left eye } \\
\text { Mean (SD) }\end{array}$ & $\begin{array}{c}\text { Right eye } \\
\text { Mean (SD) }\end{array}$ \\
\hline MD: & at T0 & $3.1(1.6)$ & $3.3(1.5)$ & $1.3(1.2)$ & $1.7(1.4)$ \\
& at T & $2.8(1.8)$ & $3.4(1.7)$ & $2.0(1.9)$ & $2.3(1.8)$ \\
\hline CLV: & at T & $4.0(2.8)$ & $3.8(2.7)$ & $1.7(1.0)$ & $2.2(1.3)$ \\
& at T12 & $4.4(3.2)$ & $5.1(4.9)$ & $2.1(1.3)$ & $2.1(1.1)$ \\
\hline Lin.C|D: & at T0 & $639.8(107.5)$ & $640.5(122.5)$ & $688.5(105.4)$ & $718.7(53.9)$ \\
& at T & $637.8(101.7)$ & $642.0(94.9)$ & $687.7(101.0)$ & $717.9(56.2)$ \\
\hline RNFL: & at T & $182.9(55.2)$ & $192.7(47.3)$ & $200.5(79.5)$ & $205.2(57.3)$ \\
& at T12 & $176.1(59.3)$ & $186.5(43.6)$ & $203.1(67.4)$ & $195.0(36.3)$ \\
\hline IOP: & at T & $17.5(2.6)$ & $17.5(2.2)$ & $15.1(2.8)$ & $16.1(3.3)$ \\
& at T & $12.7(1.2)$ & $12.0(1.7)$ & $15.0(2.4)$ & $15.8(3.0)$ \\
\hline PAC: & at T & $570.9(39.1)$ & $575.1(38.8)$ & $553(43.8)$ & $547.3(42.3)$ \\
\hline
\end{tabular}

3. Furthermore, a global negative correlation emerged between amplitude measurements on one side, and latency measurements on the other, except for P50/30' PERG latency (vectors corresponding to amplitudes and latencies, respectively, point toward opposite directions). In this case, the values of Pearson's r vary from -0.58 to -0.18 .

In Figure 1a, the points representing the eyes of NTG patients and healthy subjects show a considerable degree of separation. The latter ones (healthy subjects) are characterized by higher values of P100 VEP and P50N95 complex PERG amplitudes, and lower values of P100 VEP and P50 PERG latencies (overall, they stand on the right side of the figure), while the former (NTG) show just the opposite pattern (standing on the left side of the figure).

The measurements at $\mathrm{T}_{12}$ showed similar patterns of correlation (Fig. 1b) as those previously illustrated: that is, a positive correlation among amplitude measurements, most pronounced between the P100 VEP waves (P100/30' and P100/15'); a positive correlation among latency measurements, also most pronounced between the P100 VEP waves; and a negative correlation among latency and amplitude measurements (same as before). No other relevant relationships between variables emerged.

In the second PCA, according to the scree-plot three principal components were retained, with proportions of explained variability of data equal to $30.1 \%, 27.5 \%$, and $21.5 \%$, respectively. Given that a sound clinical interpretation was provided 

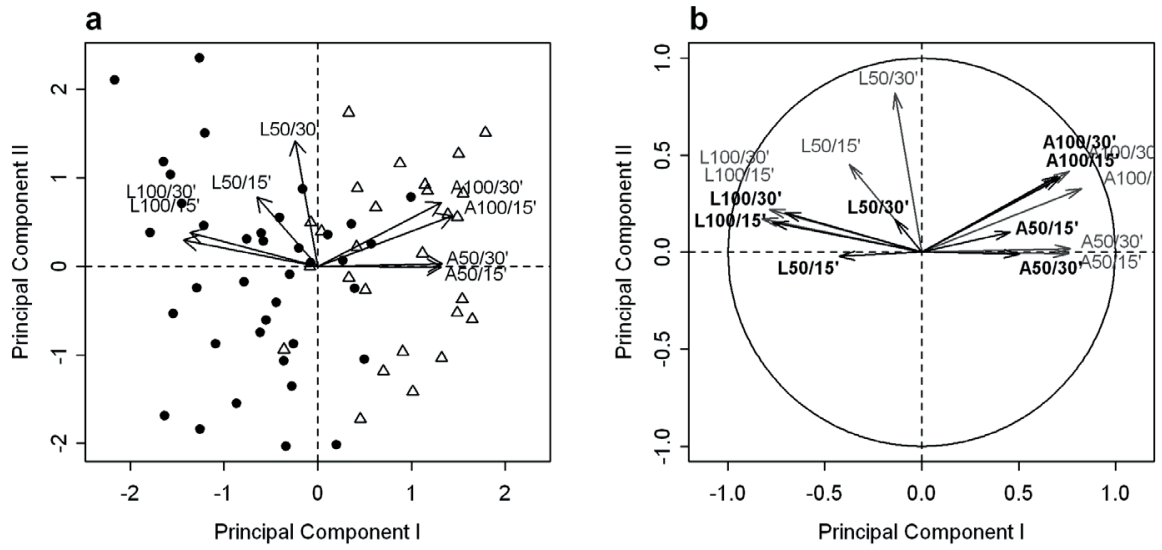

Fig. 1. Principal components of electrophysiological measurements

(a) Principal component biplot. Vectors represent the active variables: P100 VEP latencies and amplitudes at $\mathrm{T}_{0}$, with 15-minutes and 30-minutes checkerboard pattern stimulus (L100/15', L100/30', A100/15', A100/30', respectively); P50 PERG latencies and amplitudes at $\mathrm{T}_{0}$ (L50/15', L50/30', A50/15', A50/30'). Dots represent eyes of NTG patients; triangles represent eyes of healthy subjects. (b) Variables map, with active variables (gray) and passive variables (black). The passive variables were P100 VEP and P50 PERG latencies and amplitudes at $T_{12}$ (labels: same as above).
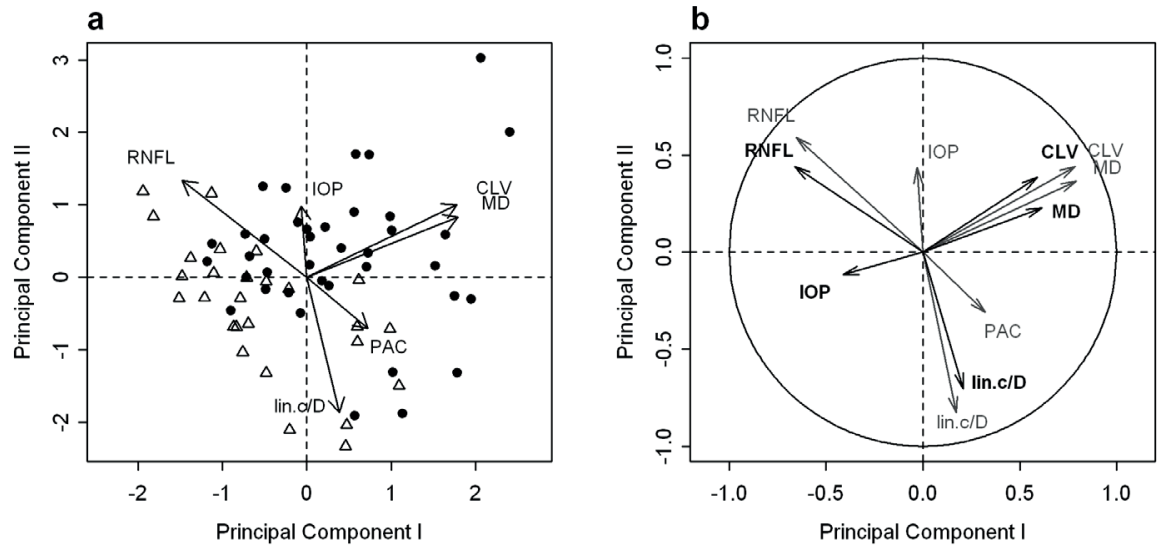

Fig. 2. Principal components of other diagnostic parameters

(a) Principal component biplot. Vectors represent the active variables: Linear C/D (lin.C/D), RNFL thickness (RNFL), mean defect (MD), correct loss variance (CLV), intraocular pressure (IOP), pachimetry (PAC); Dots represent eyes of NTG patients; triangles represent eyes of healthy subjects. (b) Variables map, with active variables (gray) and passive variables (black). The passive variables were measurements at $T_{12}$ of the variables above, except pachimetry 
Table 2. Estimated average values and differences of diagnostic parameters

NTG = eyes of patients with suspected normal tension glaucoma; Healthy = eyes of healthy subjects. Electrophysiological parameters: L100 and L50 = latency of P100 VEP and P50 PERG waves, respectively; $\mathrm{A} 100$ and A50 = amplitude of P100 VEP and P50N95 complex PERG waves, respectively. The text: $/ 15^{\prime}$ and $/ 30^{\prime}$ indicate measurements taken with 15 -minutes and 30-minutes checkerboard pattern stimulus, respectively. Visual field indices: MD = mean defect; $\mathrm{CLV}=$ correct loss variance. Morphometric parameters: RNFL = RNFL thickness; Lin. $C / D=$ linear $C / D . I O P=$ intraocular pressure. $P A C=$ pachimetry.

\begin{tabular}{|c|c|c|c|c|}
\hline \multirow[b]{2}{*}{$\begin{array}{l}\text { VEP and PERG } \\
\text { measurements }\end{array}$} & \multicolumn{2}{|c|}{ Estimated average values } & \multicolumn{2}{|c|}{ Estimated average differences } \\
\hline & $\begin{array}{l}\text { NTG } \\
\text { Est }(95 \% \mathrm{Cl})\end{array}$ & $\begin{array}{l}\text { Healthy } \\
\text { Est }(95 \% \mathrm{CI})\end{array}$ & $\begin{array}{l}\text { NTG vs Healthy: } \\
\text { Est ( } 95 \% \text { corr. } \mathrm{CI})\end{array}$ & $\begin{array}{l}\mathrm{T}_{12} \text { vs } \mathrm{T}_{0}: \\
\text { Est }(95 \% \text { corr. } \mathrm{Cl})\end{array}$ \\
\hline $\begin{array}{r}\text { L100/15': at } T_{0} \\
\text { at } T_{12}\end{array}$ & $\begin{array}{l}124.1(120.4,127.8) \\
122.3(118.7,126.0)\end{array}$ & $\begin{array}{l}111.2(106.8,115.6) \\
111.9(107.5,116.3)\end{array}$ & $\begin{array}{l}\text { at } \mathrm{T}_{0}: 12.9(5.5,20.2) \\
\text { at } \mathrm{T}_{12}: 10.5(3.2,17.8)\end{array}$ & $\begin{array}{l}\text { NTG:-1.7 }(-4.0,0.5) \\
\text { Healthy: } 0.6(-0.4,1.7)\end{array}$ \\
\hline $\begin{array}{r}\text { L100/30': at } T_{0} \\
\text { at } T_{12}\end{array}$ & $\begin{array}{l}114.3(111.2,117.5) \\
114.8(111.6,117.9)\end{array}$ & $\begin{array}{l}105.4(101.7,109.2) \\
106.0(102.2,109.8)\end{array}$ & $\begin{array}{l}\text { at } \mathrm{T}_{0}: 8.9(2.6,15.1) \\
\text { at } \mathrm{T}_{12}: 8.8(2.5,15.0)\end{array}$ & $\begin{array}{l}\text { LNG:0.5 }(-1.5,2.5) \\
\text { Healthy:0.6 }(-1.8,3.0)\end{array}$ \\
\hline $\begin{array}{r}\text { A100/15': at } T_{0} \\
\text { at } T_{12}\end{array}$ & $\begin{array}{l}8.2(6.5,9.9) \\
9.0(7.3,10.8)\end{array}$ & $\begin{array}{l}14.6(12.6,16.7) \\
14.5(12.5,16.6)\end{array}$ & $\begin{array}{l}\text { at } \mathrm{T}_{0}:-6.4(-9.8,-3.0) \\
\text { at } \mathrm{T}_{12}:-5.5(-8.9,-2.1)\end{array}$ & $\begin{array}{l}\text { NTG:0.9 }(-0.1,1.8) \\
\text { Healthy: }-0.1(-1.2,1.1)\end{array}$ \\
\hline $\begin{array}{r}A 100 / 30 \text { ': at } T_{0} \\
\text { at } T_{12}\end{array}$ & $\begin{array}{l}8.2(6.5,10.0) \\
8.4(6.7,10.1)\end{array}$ & $\begin{array}{l}13.6(11.6,15.7) \\
14.5(12.4,16.5)\end{array}$ & $\begin{array}{l}\text { at } \mathrm{T}_{0}:-5.4(-8.9,-2.0) \\
\text { at } \mathrm{T}_{12}:-6.1(-9.5,-2.6)\end{array}$ & $\begin{array}{l}\text { NTG:0.2 }(-0.8,1.2) \\
\text { Healthy:0.8 }(-0.3,2.0)\end{array}$ \\
\hline $\begin{aligned} \text { L50/15': } & \text { at } T_{0} \\
& \text { at } T_{12}\end{aligned}$ & $\begin{array}{l}62.1(59.7,64.4) \\
60.7(58.3,63.0)\end{array}$ & $\begin{array}{l}60.1(57.4,62.9) \\
58.0(55.2,60.8)\end{array}$ & $\begin{array}{l}\text { at } \mathrm{T}_{0}: 1.9(-2.7,6.5) \\
\text { at } \mathrm{T}_{12}: 2.7(-1.9,7.3)\end{array}$ & $\begin{array}{l}\text { NTG: }-1.4(-5.3,2.5) \\
\text { Healthy: }-2.1(-6.7,2.5)\end{array}$ \\
\hline $\begin{aligned} \text { L50/30': } & \text { at } T_{0} \\
& \text { at } T_{12}\end{aligned}$ & $\begin{array}{l}57.8(55.7,59.9) \\
56.4(54.2,58.5)\end{array}$ & $\begin{array}{l}56.5(54.0,59.1) \\
55.8(53.3,58.4)\end{array}$ & $\begin{array}{l}\text { at } \mathrm{T}_{0}: 1.2(-3.0,5.5) \\
\text { at } \mathrm{T}_{12}: 0.5(-3.7,4.7)\end{array}$ & $\begin{array}{l}\text { NTG: }-1.4(-4.6,1.8) \\
\text { Healthy: }-0.7(-4.5,3.1)\end{array}$ \\
\hline $\begin{aligned} \text { A50/15': } & \text { at } T_{0} \\
& \text { at } T_{12}\end{aligned}$ & $\begin{array}{l}1.5(1.2,1.7) \\
1.8(1.6,2.1)\end{array}$ & $\begin{array}{l}2.4(2.1,2.6) \\
2.5(2.2,2.8)\end{array}$ & $\begin{array}{l}\text { at } \mathrm{T}_{0}:-0.9(-1.4,-0.4) \\
\text { at } \mathrm{T}_{12}:-0.7(-1.1,-0.2)\end{array}$ & $\begin{array}{l}\text { NTG:0.3 }(0.1,0.6) \\
\text { Healthy:0.1 }(-0.2,0.5)\end{array}$ \\
\hline 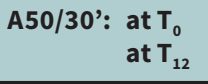 & $\begin{array}{l}1.9(1.6,2.2) \\
2.4(2.1,2.6)\end{array}$ & $\begin{array}{l}2.7(2.4,3.0) \\
2.9(2.6,3.3)\end{array}$ & $\begin{array}{l}\text { at } \mathrm{T}_{0}:-0.8(-1.3,-0.3) \\
\text { at } \mathrm{T}_{12}:-0.6(-1.1,0.0)\end{array}$ & $\begin{array}{l}\text { NTG: } 0.5(0.2,0.8) \\
\text { Healthy:0.3 }(-0.1,0.6)\end{array}$ \\
\hline $\begin{array}{r}\text { CRT/15': } \\
\text { at } T_{0} \\
\text { at } T_{12}\end{array}$ & $\begin{array}{l}61.8(58.2,65.4) \\
61.5(57.9,65.1)\end{array}$ & $\begin{array}{l}51.1(46.8,55.4) \\
53.9(49.6,58.2)\end{array}$ & $\begin{array}{l}\text { at } \mathrm{T}_{0}: 10.7(3.5,17.9) \\
\text { at } \mathrm{T}_{12}: 7.6(0.4,14.8)\end{array}$ & $\begin{array}{l}\text { NTG: }-0.3(-4.6,3.9) \\
\text { Healthy:2.8 }(-2.3,7.9)\end{array}$ \\
\hline 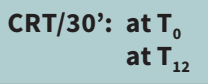 & $\begin{array}{l}61.8(58.2,65.4) \\
61.5(57.9,65.1)\end{array}$ & $\begin{array}{l}51.1(46.8,55.4) \\
53.9(49.6,58.2)\end{array}$ & $\begin{array}{l}\text { at } \mathrm{T}_{0}: 7.6(0.6,14.6) \\
\text { at } \mathrm{T}_{12}: 8.2(1.2,15.2)\end{array}$ & $\begin{array}{l}\text { NTG:1.9 }(-2.0,5.8) \\
\text { HEalthy:1.3 }(-3.3,5.8)\end{array}$ \\
\hline
\end{tabular}




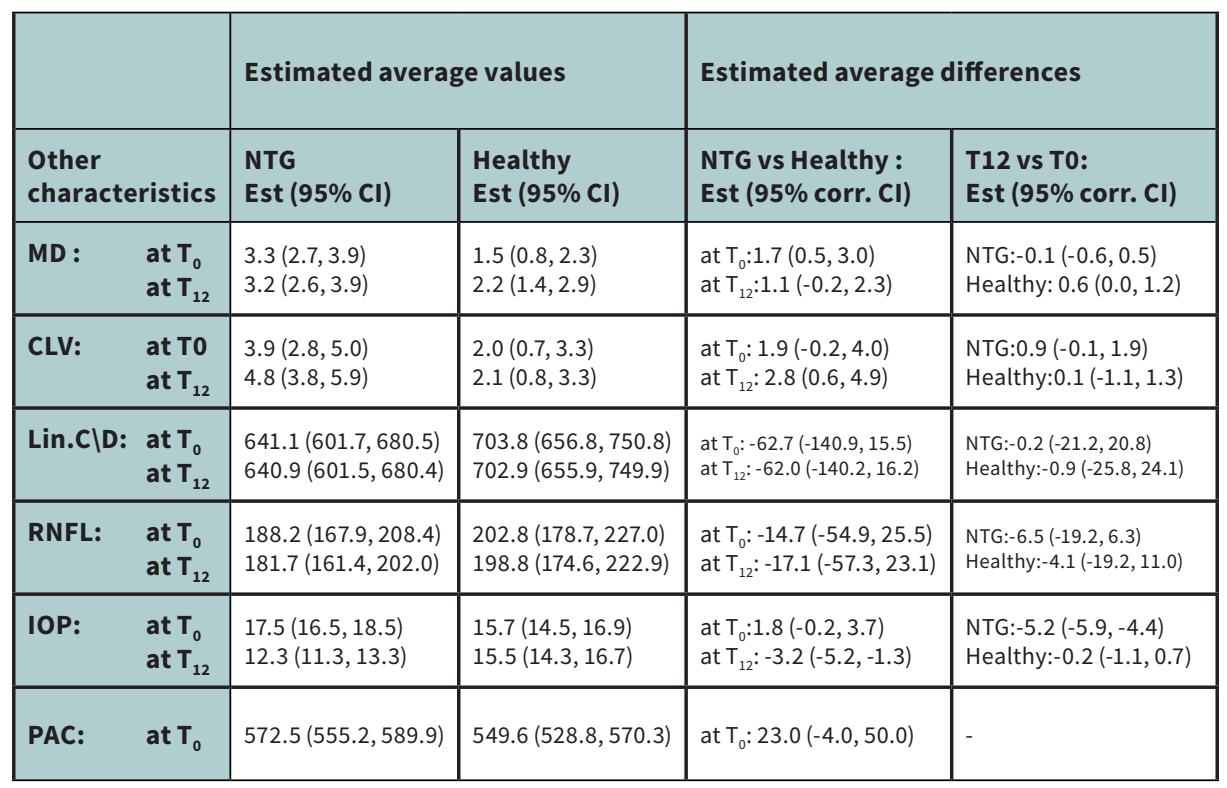

only for the first two components, the third one was excluded from the analysis. From the configuration of the vectors in Figure 2a, two major features emerge: a positive correlation between visual field defects (correlation between MD and CLV: $r=0.67$ ) and a negative correlation between morphometric parameters (correlation between RNFL and lin C/D: $r=-0.43$ )

In Figure $2 \mathrm{a}$, the eyes of NTG patients and healthy subjects show a considerable degree of separation The former are characterized by higher values of MD and CLV at $T_{0}$ (since overall they stand in the same direction of the MD and CLV vectors), while the latter are characterized by lower values of the same variables. The measurements at $\mathrm{T}_{12}$ show, overall, similar patterns of correlation (Fig. 2b).

The estimates of the average values and differences are reported in Table 2 . The average differences between eyes of NTG patients and healthy subjects of P100/15' VEP latencies are: $12.9 \mathrm{msec}(95 \% \mathrm{Cl}:(5.5,20.2) \mathrm{msec})$ at $\mathrm{T}_{0}$, and $10.5 \mathrm{msec}(95 \% \mathrm{Cl}$ : $(3.2,17.8) \mathrm{msec}$ ) at $\mathrm{T}_{12}$, suggesting that the average values in the first group (NTG) were higher. Smaller differences, also indicating a higher positive difference between the two groups, emerged for P100/30' latencies: $8.9 \mathrm{msec}(95 \% \mathrm{Cl}:(2.6,15.1) \mathrm{msec})$ at $\mathrm{T}_{0}$, and $8.8 \mathrm{msec}(95 \% \mathrm{Cl}:(2.5,15.0) \mathrm{msec})$ at $\mathrm{T}_{12}$. For amplitude measurements, lower average values for the NTG group emerged, at $\mathrm{T}_{0}$ and $\mathrm{T}_{12}$, both for the P100 VEP wave and P50N95 complex PERG amplitudes. For example, the estimated differences at $\mathrm{T}_{0}$ are: $-6.4 \mu \mathrm{V}(95 \% \mathrm{Cl}$ : $(-9.8,-3.0) \mu \mathrm{V})$ for P100/15' VEP amplitude and $-0.9 \mu \mathrm{V}(95 \% \mathrm{Cl}$ : $(-1.4,-0.4) \mu \mathrm{V})$ for P50/15' PERG amplitude. Furthermore, for P50 PERG amplitude, the average differences between $\mathrm{T}_{12}$ and $\mathrm{T}_{0}$ in the NTG group are: $0.3 \mu \mathrm{V}(95 \% \mathrm{Cl}:(0.1$, 
0.6) $\mu \mathrm{V})$ for the P50/15' amplitude and $0.5 \mu \mathrm{V}(95 \% \mathrm{Cl}:(0.2,0.8) \mu \mathrm{V})$ for the P50/30' amplitude. Such values suggest an increase in amplitude after therapy $\left(\mathrm{T}_{12}\right)$, whereas no variation in time emerged from the remaining estimates for other electrophysiological measurements. For CRT, positive differences, indicating higher values in the NTG group, emerged both at $\mathrm{T}_{0}$ and $\mathrm{T}_{12}$.

Concerning the visual field indices: for $\mathrm{MD}$, a positive average difference between NTG and healthy subjects emerged at $\mathrm{T}_{0}: 1.7 \mathrm{~dB}(95 \% \mathrm{Cl}:(0.5,3.0) \mathrm{dB})$, indicating that the average value in the NTG group was higher. Also, a positive difference between the groups is shown for CLV at $\mathrm{T}_{12}: 2.8 \mathrm{~dB}(95 \% \mathrm{Cl}:(0.6,4.9) \mathrm{dB})$. For IOP, at $\mathrm{T}_{0}$ no relevant difference emerged between NTG and healthy subjects; subsequently, the average difference between $\mathrm{T}_{12}$ and $\mathrm{T}_{0}$ indicated a reduction of IOP in the NTG group only: $-5.2 \mathrm{mmHg}(95 \% \mathrm{Cl}:(-5.9,4.4) \mathrm{mmHg})$. In agreement with this result, at $\mathrm{T}_{12}$ a negative difference between NTG and healthy subjects was found: $-5.2 \mathrm{mmHg}(95 \%$ $\mathrm{Cl}:(-5.9,-4.4) \mathrm{mmHg})$. No sensible difference emerged for the remaining variables.

\section{Discussion}

The most important problem for the correct therapy of glaucoma is early diagnosis. The current opinion is that structural changes of the optic nerve fiber layer precede functional changes measured by automated perimetry..$^{73}$ However, sometimes a manifest optic nerve cupping is not correlated with visual defects, casting doubt as to whether these patients really have glaucomatous disease that can be prevented by therapy. ${ }^{74-76}$ In this respect, intraocular asymmetry of optic disk size can aid diagnosis. ${ }^{77}$ Praecox diagnosis is more difficult in NTG because IOP values are apparently normal, ${ }^{78}$ even if larger disks seem to be more susceptible to IOP-related stress because eyes with NTG have a significantly thinner lamina cribrosa and therefore undergo significant displacement due to IOP according to mathematical finite element modeling. ${ }^{79,5}$ Neuroretinal rim loss occurs before visual field loss, ${ }^{64,80}$ but there is a linear relationship comparing 1 /lambert differential light threshold (not logarithmic (decibel) scaling) in visual field and temporal rim area. ${ }^{81}$

Among diagnostic exams, electrophysiological tests, such as VEPs and PERG, can be used to quantify RGC function. Retinal ganglion cells undergo a prolonged period of dysfunction and degeneration before cell loss. In fact, many authors have found impaired RGC function by means of electrophysiological measurement in both experimental ${ }^{82-84,44}$ and human glaucoma studies ${ }^{85}$ in subjects with OHT and early POAG with no or minimal visual field defects. ${ }^{86,54}$ In NTG there has been only one electrophysiological study: Lestak found a remarkable P100 amplitude reduction while PERG was almost unaffected. ${ }^{87}$

Likewise, some authors ${ }^{55,56}$ indicate that abnormal PERG recorded in eyes with early stages of glaucoma may often improve after IOP reduction. Therefore, this dysfunction may be partially restored after IOP reduction not only in OHT, but 
also in glaucoma patients, as well as in NTG. In the case of NTG, improvement is seen even after smaller IOP reductions because NTG eyes have a lower functional threshold. However, in patients with advanced glaucoma PERG improvement is only slight given that the amount of RGC loss is greater, limiting functional recovery.

In our study of NTG suspects, P100 amplitude VEPs was reduced and P100 latency was slightly delayed. After IOP reduction, these parameters did not show significant modification: this is understandable, as topical therapy is unlikely to have an effect on the functionality (strictly neurological) of the visual pathways. In addition, P50N95 complex amplitude was found to be lower in the NTG group than in the control group.

IOP decreased significantly after therapy, even if the baseline IOP was slightly higher than $15.5 \mathrm{mmHg}$, demonstrating that these patients had, in fact, NTG, as explained above. Otherwise, P50N95 complex amplitude rose slightly; this is correlated to IOP lowering, also for slight values. ${ }^{88}$ There is no inverse correlation between the amount of P50 amplitude increase and IOP reduction.

IOP reduction is correlated to the effective presence of glaucoma; in fact, IOP reduction in normal eyes does not modify P50N95 complex amplitude at all. Therefore, an increase in P50N95 complex PERG amplitude following a decrease in IOP is suggestive of dysfunction in suspected glaucoma (in this study, NTG); this dysfunction could be partially restored after hypotonizing. ${ }^{56}$

Morphometric parameters, i.e., RNFL and linear C/D showed no modification in the NTG suspect group one year after hypotonizing therapy, and neither did visual field indices (MD and CLV). If there is only RGC dysfunction, it is unlikely that optic nerve head changes would be apparent. ${ }^{89}$ In this sense, electrophysiological tests could provide a more sensitive measure of RGC integrity.

This pilot study is the first to attempt to differentiate between normal patients with apparent larger disc cupping and NTG suspects with quite normal visual fields. This diagnostic approach may provide important information to avoid starting useless therapy, or, on the contrary, to start precociously hypotonizing therapy in NTG suspects before visual field loss occurs.

Finally, electrophysiological tests could also be used in a similar fashion to the visual field test, but with greater sensibility, allowing ophthalmologists to monitor personalized therapy and even change its course by providing functional information. Furthermore, these tests may provide an objective and indisputable assessment of the effectiveness of neuroprotective therapies.

\section{References}

1. Heijl A, Leske MC, Bengtsson B, Hyman L, Hussein M. Reduction of intraocular pressure and glaucoma progression: results from the early manifest glaucoma trial. Arch Ophthalmol 2002;120:1268-1279. 
2. Kass MA, Heuer DK, Higginbotham EJ, Johnson CA, Keltner JL, Miller JP, et al. The ocular hypertension treatment study: a randomized trial determines that topical ocular hypotensive medication delays or prevents the onset of primary open-angle glaucoma. Arch Ophthalmol 2002;120:701-713.

3. Krupin T. Special considerations in low-tension glaucoma. Can. J. Ophthalmol 2007;42(3):414-417. Available from: http://article.pubs.nrc-cnrc.gc.ca/RPAS/rpv?hm=HInit\&calyLang=eng\&journal=cjo\&volume=42\&afpf=i07-043.pdf doi: 10.3129/i07-043.

4. Sowka J. New thoughts on normal tension glaucoma. Optometry - Journal of the American Optometric Association 2005;76(10):600-608. Available from: http://linkinghub.elsevier.com/retrieve/pii/ S1529183905001387 doi: 10.1016/j.optm.2005.08.020.

5. Hayamizu F, Yamazaki Y, Nakagami T, Mizuki K. Opic disc size and progression of visual field damage in patients with normal-tension glaucoma. Clinical Opthalmology 2013;7:807-813.

6. Bonomi L, Marchini G, Marraffa M. et al Prevalence of glaucoma and intraocular distribution in a definite population. The Enge-Neumarkt Study. Ophthalmology 1998;105(2):209-215. Available from: http://linkinghub.elsevier.com/retrieve/pii/S0161642098926653 doi: 10.1016/S0161-6420(98)926653.

7. Dielemans I, Vingerling JR, Wolfs RC, et al. The prevalence of primary open angle glaucoma in a population based study in the Netherlands. The Rotterdam Study. Ophthalmology 1994;101(11):18511855. Available from: http://linkinghub.elsevier.com/retrieve/pii/S0161642094310906 doi: 10.1016/ S0161-6420(94)31090-6.

8. group, n.t.g.s. (Collaborative). Collaborative normal tension glaucoma study group. Comparison of glaucomatous progression between untreated patients with normal-tension glaucoma and patients with therapeutically reduced intraocular pressures. Am J Ophthalmol 1998;126:126-487.

9. group, n.t.g.s. (Collaborative) . Collaborative normal tension glaucoma study group. The effectiveness of intraocular pressure reduction in the treatment of normal tension glaucoma. Am J Ophthalmol 1998;126:126-498.

10. group, n.t.g.s. (Collaborative) . Collaborative normal tension glaucoma study group. Risk factors for progression of visual field abnormalities in normal tension glaucoma. Am J Ophthalmol 2001 2001;131:699-708.

11. group, n.t.g.s. (Collaborative) . Collaborative normal tension glaucoma study group. Factors that predict the benefit of lowering intraocular pressure in normal tension glaucoma. Am J Ophthalmol 2003;2003:136-820.

12. Sergi M, Salerno DE, Rizzi M, Blini M, Andreoli A. Messenio D, pecis M, Bertoni G: Prevalence of normal tension glaucoma in obstructive sleep apnea syndrome patients. J Glaucoma 2007 2007;16:42-46.

13. Meyer JH, Brandi- Dohrn J, , Funk J. Twenty four hour blood pressure monitoring in normal tension glaucoma. Br J Ophthalmol 1996;80(10):864-867. Available from: http://bjo.bmj.com/cgi/ doi/10.1136/bjo.80.10.864 doi: 10.1136/bjo.80.10.864.

14. Collignon N, Dewe W, Guillaume S, Collignon-Brach J. Ambulatory blood pressure monitoring in glaucoma patients. The nocturnal systolic dip and its relationship with disease progression. Int Ophthalmol 1998;22:19-25.

15. Liu JH. Diurnal measurement of intraocular pressure. J Glaucoma 2001 2001;10:39-41.

16. Gupta N, Yucel YH. Glaucoma in the brain: a piece of the puzzle. Can J Ophthalmol 2006;41(5):541542. Available from: http://linkinghub.elsevier.com/retrieve/pii/S0008418206800220 doi: 10.1016/ S0008-4182(06)80022-0.

17. Weber AJ, Harman C. Structure-function relations of parasol in the normal and glaucomatous primate retina. Invest Ophthalmol Vis Sci 2005;46:3197-3207.

18. Yucel YH, Zhand Q, Gupta N, Kaufman PL, Weinreb RN. Loss of neurons in magnocellular and parvocellular layers of the lateral geniculate nucleus in glaucoma. Arch Ophthalmol 2000;118(3):378-384. Available from: http://archopht.jamanetwork.com/article.aspx?doi=10.1001/archopht.118.3.378 doi: 10.1001/archopht.118.3.378.

19. Yucel YH, Zhang Q, Weinreb RN, Kaufman PL, Gupta N. Effects of retinal ganglion cell loss on magno-, parvo-, koniocellular pathways in the lateral geniculate nucleus and visual cortex in glaucoma. Prog 
Retin Eye Res 2003 2003;22(4):465-481. Available from: http://linkinghub.elsevier.com/retrieve/pii/ S1350946203000260 doi: 10.1016/S1350-9462(03)00026-0.

20. Gupta N, Glaucoma YYH, brain t. . J Glaucoma 2001;10:28-29.

21. Maffei L, Fiorentini A. Electroretinographic responses to alternating gratings before and after section of the optic nerve. Science 1981;211(4485):953-954. Available from: http://www.sciencemag.org/ cgi/doi/10.1126/science.7466369 doi: 10.1126/science.7466369.

22. Bach M, Gerling J, Geiger . K: Optic atrophy reduces the pattern-electroretinogram for both fine and coarse stimulus pattern. Clin Vis Sci 1992:327-333.

23. Trick GL, Neshe R, Cooper DG. et al: The human pattern ERG: alterations of response properties with aging. Optom Vis Sci 1992;69(2):122-128. Available from: http://content.wkhealth.com/linkback/ openurl?sid=WKPTLP:landingpage\&an=00006324-199202000-00005 doi: 10.1097/00006324$199202000-00005$.

24. Porciatti V, Burr DC, Morrone MC, Fiorentini . A The effects of aging on the pattern electroretinogram and visual evoked potentials in humans: Vision Res. 1992;32:1199-1209.

25. Bach M. Electrophysiological approaches for early detection of glaucoma. Eur J Ophthalmol 2001; 25. suppl 2001;2:41-49.

26. Bach M, Hoffmann MB. Update on the Pattern Electroretinogram in Glaucoma. Optometry and Vision Science 2008;85(6):386-395. Available from: http://content.wkhealth.com/ linkback/openurl?sid=WKPTLP:landingpage\&an=00006324-200806000-00009 doi: $10.1097 / O P X$ .0b013e318177ebf3.

27. Van_den_Berg TJ. Riemslag FC, de Vos GW, Verduyn Lunel HF. Pattern ERG and glaucomatous visual field defects. Doc Ophthalmol 1986;61(3-4):335-341. Available from: http://link.springer. com/10.1007/BF00142361 doi: 10.1007/BF00142361.

28. Bach M, Sulimma F, Gerling J. Little correlation of the pattern electroretinogram (PERG) and visual filed measures in early glaucoma. Doc Ophthalmol 1997;94(3):253-263. Available from: http://link. springer.com/10.1007/BF02582983 doi: 10.1007/BF02582983.

29. Quigley HA, Addicks EM, Green . WR: Optic nerve damage in human glaucoma. III Quantitative correlation of nerve fiber loss and visual field defect in glaucoma, ischemic neuropathy, papilledema and toxic neuropathy. Arch Ophthalmol 1982;100:100-135.

30. Porciatti V, Falsini B, Brunori S, et al. Pattern electroretinogram as a function of spatial frequency in ocular hypertension and early glaucoma. Doc Ophthalmol 1987;65(3):349-355. Available from: http://link.springer.com/10.1007/BF00149941 doi: 10.1007/BF00149941.

31. Ventura LM, Porciatti DS. Restoration of retinal ganglion cell function in early glaucoma after intraocular pressure reduction. A pilot study. Ophthalmology 2005;112(1):20-27. Available from: http:// linkinghub.elsevier.com/retrieve/pii/S0161642004014630 doi: 10.1016/j.ophtha.2004.09.002.

32. Caprioli J, Sears M, Miller JM. Patterns of early visual field loss in open-angle glaucoma. Am J Ophthalmol 1987;104(1):98-98. Available from: http://linkinghub.elsevier.com/retrieve/ pii/000293948790314X doi: 10.1016/0002-9394(87)90314-X.

33. Wanger P, Persson . HE: Pattern-reversal electroretinograms in unilateral glaucoma. Invest Ophthalmol Vis Sci. 1983;24:749-753.

34. Papst N, Bopp M, Schnaudigel OE. The pattern evoked electroretinogram associated with elevated intraocular pressure. Graefe's archive for clinical and experimental ophthalmology 1984 Oct;222(1):34-7. Available from: http://link.springer.com/10.1007/BF02133775 doi: 10.1007/ BF02133775.

35. Price MJ, Drance SM, Price M, Schulzer M, Douglas GR, Tansley B. The pattern electroretinogram and visual-evoked potential in glaucoma. Graefe's archive for clinical and experimental ophthalmology 1988 Nov;226(6):542-7. Available from: http://link.springer.com/10.1007/BF02169202 doi: 10.1007/ BF02169202.

36. Weinstein GW, Arden GB, Hitchings RA. The pattern electroretinogram (PERG) in ocular hypertension and glaucoma. Arch Ophthalmol 1988;106(7):923-928. Available from: http://archopht.jamanetwork.com/article.aspx?articleid=637346 doi: 10.1001/archopht.1988.01060140069027. 
37. Arai M, Yoshimura N, Sakaue H, Chihara E, Honda Y. A 3-year follow-up study of ocular hypertension by pattern electroretinogram. Ophthalmologica 1993;207(4):187-95. Available from: http://www. karger.com/doi/10.1159/000310431 doi: 10.1159/000310431.

38. Fj GI, Fj FT, Almarcegui Lafita C, , Polo Llorens V, , Sanches Perez A . Honrubia Lopez FM. Predictive value of the pattern-electroretinogram in glaucoma (in. Spanish). Arch Soc Esp Oftalmol 2001;76:485491.

39. Unsoeld AS, Walter S, Meyer J, Funk J, Bach M. Pattern ERG as an early risk indicator in ocular hypertension - a 9-year prospective study. Invest Ophthalmol Vis Sci (Suppl): S146.2001.

40. Bach M, Unsoeld AS, Philippin H, et al. Pattern ERG as an early indicator in ocular hypertension: a long -term prospective study. Invest Ophthalmol Vis Sci 2006;47(11):4881-4887. Available from: http://iovs.arvojournals.org/article.aspx?doi=10.1167/iovs.05-0875 doi: 10.1167/iovs.05-0875.

41. Pfeiffer N, Tillmon B, Bach M. Predictive value of pattern electroretinogram in high-risk ocular hypertension. Invest Ophthalmol Vis Sci 1993;34:1710-1715.

42. Philippin H, Unsoeld A, Maier P, Walter S, Bach M, Funk J. Ten-year results: detection of long-term progressive optic disc changes with confocal laser tomography. Graefes Arch Clin Exp Ophthalmol 2005;244:1-5.

43. Marx MS, Podos SM, Bodis-Wollner I. et al: Signs of early damage in glaucomatous monkey eyes: low spatial frequency losses in the pattern. ERG and VEP. Exp Eye Res 1988:46-173.

44. Saleh M, Nagaraju M, Porciatti V. Longitudinal evaluation of retinal ganglion cell function and IOP in the DBA/2J mouse model of glaucoma. Invest Ophthalmol Vis Sci 2007;48(10):4564-4572. Available from: http://iovs.arvojournals.org/article.aspx?doi=10.1167/iovs.07-0483 doi: 10.1167/iovs.07-0483.

45. Porciatti V, Saleh M, Nagaraju M. The pattern electroretinogram as a tool to monitor progressive retinal ganglion cell dysfunction in the DBA/2J mouse model of glaucoma. Invest Ophthalmol Vis Sci 2007;48(2):745-751. Available from: http://iovs.arvojournals.org/article.aspx?doi=10.1167/iovs.060733 doi: 10.1167/iovs.06-0733.

46. Ventura LM, Porciatti V. Pattern electroretinogram and glaucoma. Curr Opin Ophthalmol 2006;17(2):196-202. Available from: http://content.wkhealth.com/linkback/ openurl?sid=WKPTLP:landingpage\&an=00055735-200604000-00013 doi: 10.1097/01. icu.0000193082.44938.3c.

47. Parisi V, Manni G, Centofanti M, Gandolfi SA, Olzi D, Bucci MG. Correlation between optical coherence tomography, pattern electroretinogram, and visual evoked potentials in open-angle glaucoma patients. Ophthalmology 2001 May;108(5):905-12. Available from: http://linkinghub.elsevier.com/ retrieve/pii/S0161642000006448 doi: 10.1016/S0161-6420(00)00644-8.

48. Ventura LM, Sorokac N, De_Los Santos R, , Feuer WJ. Porciatti V: The relationship between retinal ganglion cell function and retinal nerve fiber thickness in early glaucoma. Invest Ophthalmol Vis Sci 2006;47:3904-3911.

49. Salgarello T, Colotto A, Falsini B. et al: Correlation of pattern electroretinogram with optic disc cup shape measure in ocular hypertension. Invest Ophthalmol Vis Sci 1999;40:1989-1997.

50. Salgarello T, Falsini B, Stifano G. et al: Morpho-functional follow-up of the optic nerve in treated ocular hypertension: disc morfometry and steady-state pattern electroretinogram. Curr Eye Res 2008;33(8):709-721. Available from: http://www.tandfonline.com/doi/ full/10.1080/02713680802277692 doi: 10.1080/02713680802277692.

51. Parisi V, Miglior S, Manni G, Centofanti M, Bucci . M: Clinical ability of pattern electroretinograms and visual evoked potentials in detecting visual dysfunction in ocular hypertension and glaucoma. Ophthalmology; 2006.

52. Bayer AU, Maag KP, Erb C, , Detection of optic neuropathy in glaucomatous eyes with normal standard visual fields using a test battery of short-wavelength automated perimetry and pattern electroretinography. 2002;109:1350-1361.

53. Ventura LM, Porciatti V, et al. Pattern electroretinogram abnormality and glaucoma. Ophtalmology 2005;112(1):10-19. Available from: http://linkinghub.elsevier.com/retrieve/pii/S0161642004012606 doi: 10.1016/j.ophtha.2004.07.018. 
54. Hood DC, Xu L, Thienprasiddhi P, Greenstein VC. Odel JG, Grippo TM, Liehmann JM, Rithc R: The pattern electroretinogram in glaucoma patients with confirmated visual field deficit. Invest Opthalmol Vis Sci 2005 2005;46:2411-2418.

55. Ventura LM, Porciatti DS. Restoration of retinal ganglion cell function in early glaucoma after intraocular pressure reduction. A pilot study. Ophthalmology 2005;112(1):20-27. Available from: http:// linkinghub.elsevier.com/retrieve/pii/S0161642004014630 doi: 10.1016/j.ophtha.2004.09.002.

56. North RV, Jones AL, Drasdo N, Wild JM, Morgan JE. Electrophysiological evidence of early functional damage in glaucoma and ocular hypertension. Inv Ophthalmol Vis Sci 2010;51(2):1216-1222. Available from: http://iovs.arvojournals.org/article.aspx?doi=10.1167/iovs.09-3409 doi: 10.1167/iovs.09-3409.

57. Ventura LM, Feuer JW, Porciatti V. Progressive loss of retinal ganglion cell function is hindered with IOP-lowering treatment in early glaucoma. Invest Ophthalmol Vis Sci 2012;53(2):659-663. Available from: http://iovs.arvojournals.org/article.aspx?doi=10.1167/iovs.11-8525 doi: 10.1167/iovs.11-8525.

58. Marx MS, Podos SM, et al. Flash and pattern electroretinograms in normal and laser-induced glaucomatous primate eyes. Invest Ophthalmol Vis Sci 1986;27:378-386.

59. Parisi V, Pernini C, Guinetti C, et al. Electrophysiological assesment of visual pathways in glaucoma. Eur J Ophthalmol 1997;7:229-235.

60. Horn FK, Jonas JB, Budde WM, Junemann AM, Mardin CY, Korth M. Monitoring glaucoma progression with visual evoked potentials of the blue-sensitive pathway. Invest Ophthalmol Vis Sci 2002;43:18281834.

61. Celesia GG, Kaufman D, Cone SB. Simultaneous recording of pattern electroretinography and visual evoked potentials in multiple sclerosis. A method to separate demyelination from axonal damage to the optic nerve. Arch Neurol 1986;43(12):1247-1247. Available from: http://archneur. jamanetwork.com/article.aspx?doi=10.1001/archneur.1986.00520120031012 doi: $10.1001 /$ archneur.1986.00520120031012.

62. Brusini P. Clinical use of a new method for visual field damage classification in glaucoma. Eur J Ophthalmol 1996;6:402-407.

63. Brusini P, Filacorda S. Enhanced Glaucoma Staging System (GSS 2) for Classifying Functional Damage in Glaucoma. Journal of Glaucoma 2006;15(1):40-46. Available from: http://content.wkhealth.com/ linkback/openurl?sid=WKPTLP:landingpage\&an=00061198-200602000-00010 doi: 10.1097/01. ijg.0000195932.48288.97.

64. Garway-Heath DF, Wollstein G, Hitchings RA. Agong changes of the optic nerve head in relationship to open angle glaucoma. Br J Ophthalmol 1997;81(10):840-845. Available from: http://bjo.bmj.com/ cgi/doi/10.1136/bjo.81.10.840 doi: 10.1136/bjo.81.10.840.

65. Kamal DS, Viswanathan AC, Garway-Heath DF, et al. Detection of optic disc change in ocular hypertensives converting to early glaucoma. Br J Ophthalmol 1999;83(3):290-294. Available from: http:// bjo.bmj.com/cgi/doi/10.1136/bjo.83.3.290 doi: 10.1136/bjo.83.3.290.

66. Medvev N, Cvenkel B. Diagnostic accuracy of the Moorfields Regression Analysis using the Heidelberg Retina Tomography in glaucoma patients with visual field defects. Eur J Opthalmol 2007 2007;17(17):216-222.

67. Jolliffe I. Principal component analysis. John Wiley \& Sons, Ltd; 2002.

68. Gabriel KR. The biplot graphic display of matrices with application to principal component analysis. Biometrika 1971:58-3.

69. Murdoch IE, Morris SS, Cousens SN. People and eyes: statistical approaches in ophthalmology. British Journal of Ophthalmology 1998 Aug;82(8):971-973. Available from: http://bjo.bmj.com/cgi/ doi/10.1136/bjo.82.8.971 doi: 10.1136/bjo.82.8.971.

70. Team RC R http www R-project org. A Language and Environment for Statistical Computing (Version 3.1. 2): R Foundation for Statistical Computing. Vienna, Austria. Available from URL 2015.

71. Pinheiro J, Bates D, DebRoy S, Sarkar D, Core R. Team 2015. nlme: Linear and Nonlinear Mixed Effects Models_. R package version 3.1. URL: http: CRAN.R-project.org/package=nlme; .

72. Hothorn T, Bretz F, Westfall P. Simultaneous Inference in General Parametric Models. Biometrical Journal 2008;50(3):346-363. 
73. Sommer A, Tielsch JM, Katz J, et al. Clinically detectable nerve fiber atrophy precedes the onset of glaucomatous field loss. Arch Ophthalmol 1991;109(1):77-83. Available from: http://archopht. jamanetwork.com/article.aspx?doi=10.1001/archopht.1991.01080010079037 doi: $10.1001 /$ archopht.1991.01080010079037.

74. Burk RO, Rohrschneider K, Noack H, Volker HE. Are large optic nerve heads susceptible to glaucomatous damage at normal intraocular pressure? A three-dimensional study by laser scanning tomography. Greafes Arch Clin Exp Ophthalmol 1992;230(6):552-560. Available from: http://link.springer. com/10.1007/BF00181778 doi: 10.1007/BF00181778.

75. Wang L, Damji KF, Munger R, et al. Increased disk size in glaucomatous eyes versus normal eyes in the Reykjavik eye study. Am J Ophthalmol 2003;135(2):226-228. Available from: http://linkinghub. elsevier.com/retrieve/pii/S0002939402019281 doi: 10.1016/S0002-9394(02)01928-1.

76. Jb J, Xu L, Zhang L, Wang Y. Optic disc size in chronic glaucoma: the Beijng eye study. Am J Ophthalmol 2006;142(1):168-170. Available from: http://linkinghub.elsevier.com/retrieve/pii/ S0002939406001905 doi: 10.1016/j.ajo.2006.01.068.

77. Tomita G, Nyman K, Raitta C, Kawamura M. Intraocular asymmetry of optic disc size and its relevance to visual field loss in normal-tension glaucoma. Graefes Arch Clin Exp Ophthalmol 1994;232(5):290296. Available from: http://link.springer.com/10.1007/BF00194478 doi: 10.1007/BF00194478.

78. Jonas JB, Sturmer J, Papastathopoulos KI, Meier-Gibbons F, Dichtl A. Optic disc size and optic nerve damage in normal pressure glaucoma. British Journal of Ophthalmology 1995 Dec;79(12):1102-1105. Available from: http://bjo.bmj.com/cgi/doi/10.1136/bjo.79.12.1102 doi: 10.1136/bjo.79.12.1102.

79. Bellezza AJ, Hart RT, Burgoyne CF. The optic nerve head as a biomechanical structure: initial finite element modeling. Investigative ophthalmology \& visual science 2000. ;41(10):2991-3000.

80. Tuulonen A, Lehtola J, Airaksinen PJ. Nerve fiber layer defects with normal visual field: do normal optic disc and normal visual field indicate absence of glaucomatous abnormality. Ophthalmology 1993;100(5):587-597. Available from: http://linkinghub.elsevier.com/retrieve/pii/ S0161642093315988 doi: 10.1016/S0161-6420(93)31598-8.

81. Garway-Heath DF, Holder GE, Fizke FW, et al. Relationship between electrophysiological, psychophysiological and anatomical measures in glaucoma. Invest Ophthalmol Vis Sci 2002;43:2213-2220.

82. Harwerth RS, Crawford M, Frishman LJ, et al. Visual field defects and neural losses from experimental glaucoma. Prog Retin Eye Res 2002;21(1):91-125. Available from: http://linkinghub.elsevier.com/ retrieve/pii/S1350946201000222 doi: 10.1016/S1350-9462(01)00022-2.

83. Swanson WH, Felius J, Pan F. Perimetric defects and ganglion cell damage: interpreting linear relations using a two-stage neural model. Invest Ophthalmol Vis Sci 2004;45(2):466-472. Available from: http://iovs.arvojournals.org/article.aspx?doi=10.1167/iovs.03-0374 doi: 10.1167/iovs.03-0374.

84. Marx MS, Podos SM, Bodis-Wollner . pattern electroretinograms in normal and laser-induced glaucomatous primate eyes. Invest Ophthalmol Vis Sci 1986;27:378-386.

85. Kerrigan-Baumrind LA, Quigley HA, Pease ME, et al. Number of ganglion cells in glaucoma eyes compared with threshold visual filed tests in the same persons. Invest Ophthalmol Vis Sci 2000;41:741-748.

86. Neoh C, Kaye SB, Brown M, et al. Pattern electroretinogram and automated perimetry in patients with glaucoma and ocular hypertension. Br J Ophthalmol 1994;78(5):359-362. Available from: http:// bjo.bmj.com/cgi/doi/10.1136/bjo.78.5.359 doi: 10.1136/bjo.78.5.359.

87. Lestak J, Elena N, Sarka P, Krejcova H, Bartosova L, High FV. tension versus normal tension glaucoma. A comparison of structural and functione examinations. J Clinic Experiment Ophthalmol;2012:1-4.

88. Karaskiewicz J, Drobek-Slowik M, Libinski W. Pattern electroretinogram (PERG) in the early diagnosis of normal-tension glaucoma: a case report. Doc Ophthalmol 2014;128(1):53-58. Available from: http://link.springer.com/10.1007/s10633-013-9414-x doi: 10.1007/s10633-013-9414-x.

89. Falsini B, Marangoni D, Salgarello T, et al. Structure-function relationship in ocular hypertension and glaucoma: interindividual and interocular analysis by OCT and pattern ERG. Graefes Arch Clin Exp Ophthalmol 2008;246(8):1153-1162. Available from: http://link.springer.com/10.1007/s00417-0080808-5 doi: 10.1007/s00417-008-0808-5. 